\title{
Kablolu İHA Sistemleri ve Uygulamaları
}

\author{
Ali Küçükçelebi ${ }^{1}$, Ercan Yaldız $^{2}$ \\ ${ }^{1}$ Konya Teknik Üniversitesi, Mühendislik Fakültesi, Elektrik-Elektronik Mühendisliği Bölümü, Konya, Türkiye (ORCID: 0000-0001-6565-8477) \\ ${ }^{2}$ Konya Teknik Üniversitesi, Mühendislik Fakültesi, Elektrik-Elektronik Mühendisliği Bölümü, Konya, Türkiye (ORCID: 0000-0003-2245-0654)
}

( $1^{\text {st }}$ International Conference on Computer, Electrical and Electronic Sciences ICCEES 2020 - 8-10 Ekim 2020)

(DOI: 10.31590/ejosat.802734)

ATIF/REFERENCE: Küçükçelebi, A. \& Yaldız, E. (2020). Kablolu İHA Sistemleri ve Uygulamaları. Avrupa Bilim ve Teknoloji Dergisi, (Özel Say1), 154-159.

\section{Öz}

Son yıllarda İHA sistemlerinin sivil ve askeri kullanımı hızla artmaktadır. Ancak uçuş sürelerinin kısa olması ve faydalı yük kapasitelerinin düşük olması gibi önemli kullanım kısıtları mevcuttur. Gelişen teknolojiyle birlikte İHA'ların bu kullanım kısıtlarına çözüm önerisi olarak farklı yapılarda İHA sistemleri tasarlanmıştır. Kablolu drone sistemleri ve kablolu aerostat sistemleri genel kabul görmüş çözümlerden birkaçıdır. Kablolu drone sistemleri daha düşük irtifalarda kesintisiz görev yapabilen drone temelli bir çözümdür. Bu çalışmalar sayesinde farklı uygulama alanlarında hizmet verilmeye başlanmıştır. Bu çalışmada İHA sistemleri ile bu sistemlerin avantaj ve dezavantajları sunulmuştur. Ayrıca kablolu drone ve kablolu aerostatların çalışma yapıları anlatılmış ve kullanım alanlarıyla ilgili örnekler verilmiştir.

Anahtar Kelimeler: İHA Teknolojisi, Kablolu İHA, Aerostat, Drone, Keşif, Gözetleme.

\section{Tethered UAV Systems and Applications}

\begin{abstract}
Civil and military use of UAV systems has been increasing rapidly in recent years. However, there are important usage limitations such as short flight times and low useful load capacities. With the developing technology, UAV systems with different structures have been designed as a solution to these usage limitations of UAVs. Tethered drone systems and tethered aerostat systems are some of the generally accepted solutions. Tethered drone systems are a drone-based solution that can operate at lower altitudes without interruption. Thanks to these studies, services have started to be provided in different application areas. In this study, the advantages and disadvantages of the UAV systems were mentioned and a comparison was made on flight times. In addition, the working structures of tethered drones and tethered aerostats are explained and examples of their usage areas are given.
\end{abstract}

Keywords: UAV Technology, Tethered UAV, Aerostat, Drone, Exploration, Surveillance.

\section{Giriş}

İçerisinde bulunduğumuz dönemde radar, elektro-optik ve kamera sistemlerinde büyük gelişim sağlanmıştır. Bu gelişmelere bağlı olarak keşif ve gözetleme çalışmaları bu sistemler üzerine kurulmaya başlanmıştır. Günümüzdeki en etkili keşif ve gözetleme yöntemlerden biri de İnsansız Hava Aracı (IHHA) üzerinden gerçekleştirilmektedir (Kabadayı ve Uysal, 2019; Bayraktar, 2013). Askeri ve savunma amaçlı İHA sistemlerinin kullanımının yanı sıra sivil alanlarda da kullanılmaya başlanmıştır (Bajoria ve ark., 2017). Fakat zamanla İHA sistemlerinde çeşitli kullanım kısıtları uygulama alanlarında sorun yaratmaya başlamıştır. Uçuş sürelerinin kısa olması ve faydalı yük kapasitelerinin düşük olması bu kullanım kısıtlarının en önemlilerinden birkaçıdır (Balasubramanian ve ark., 2014; Pant, Komerath ve Kar, 2011). Bu soruna bir çözüm önerisi olarak kablolu İHA sistemleri ve modelleri geliştirilmektedir. Bu tür İHA sistemleri keşif ve gözetleme için gerek duyulan faydalı yükleri istenilen irtifalara çıarabilme kabiliyetine sahiptir. Kablolu İHA sistemlerinin kullanımı son yıllarda dünya genelinde artmıştır. Taşıdıkları kameralar vs. sayesinde kritik tesislerde güvenlik amaçlı kullanımları mevcuttur. Askeri bölgelerde ise devriye araçlarının üzerinde kullanılarak oluşabilecek tehlikelere karşı ek bir önlem olarak kullanılmaktadır. Kablolu aerostat sistemleri ise daha yüksek irtifalarda uzun süreler boyunca havada kalma kabiliyetlerine sahiptirler (Pant, Komerath ve Kar, 2011). Dünya genelinde gelişmiş ülkelerin çoğu kablolu aerostat sistemlerini keşif ve gözetleme 
amaçlı sınır bölgelerinde ve olası terör eylemlerinin olabileceği bölgelerde sıklıkla kullanmaktadırlar. 2015 yılından itibaren Türkiye'de bazı firmalar bu tür sistemler için çalışmalara başlamıştır (Karaağaç, 2016).

\section{2. İHA Sistemleri ve İha Uçuş Süreleri}

İHA'lar çoğunlukla bir yer kontrol istasyonundan kontrol edilen, pilota ihtiyaç duymadan kullanılabilen hava araçlarına verilen genel bir isimdir. İHA'lar elektronik ve yazılım teknolojilerindeki ilerlemelerle paralel olarak hızla gelişmektedir. İHA'lar ilk zamanlarda sadece askeri amaçlı görevler için geliştirilmiş olsa da günümüzde sivil ve ticari amaçlı kullanımı da büyük oranda artmıştır.

Günümüzde kullanılan İHA sistemlerinin en büyük problemlerinden biri güç kapasitesine bağlı olarak havada kalma sürelerinin kısıtlı olmasıdır. Tablo 1'de İHA'ların sınıflarına göre havada kalma süreleri verilmiştir.

Tablo 1. IHA Sınıfları ve Uçuş Süreleri (Yiğit, Yazar ve Karakoç, 2018)

\begin{tabular}{|c|c|}
\hline İHA SINIFI & Uçuş Süresi (saat) \\
\hline Mikro /Mini İHA & $1-2$ \\
\hline Taktiksel İHA & $2-48$ \\
\hline Stratejik İHA & $24-48$ \\
\hline Özel Görevli İHA & $3->48$ \\
\hline
\end{tabular}

Son yıllarda birçok havacılık firması özgün tasarımlar ile bu uçuş sürelerini yükseltme yarışına girmiş bulunmaktadır. Airbus firmasının üretmiş olduğu Zephry Stratosferik İHA yaklaşık olarak 25 gün kesintisiz olarak havada kalarak bu alandaki rekoru elinde bulundurmaktadır. Aurora Flight Sciences firması tarafından tasarlanan Orion isimli İHA ise uçuş testleri sırasında 120 saat havada kalmayı başarmıştır (Airforce-Technology, 2020). Son olarak Türk Havacılık ve Uzay Sanayii firmasının geliştirmiş olduğu Aksungur isimli İHA ise 49 saat havada kalmayı başarmıştır (St Endustri, 2020).

\section{1. İHA'ların Avantaj ve Dezavantajları}

\section{Avantajları:}

- Oluşabilecek kazalarda can kaybı yaşanma ihtimali oldukça düşüktür.

- Pilot yetiştirme maliyeti düşüktür.

- Ulaşılamayan bölgeler için kullanılabilir.

- Yapım maliyeti normal bir uçağa kıyasla daha düşüktür.

\section{Dezavantajları:}

- Havada kalma süreleri kısadır.

- Uçuş irtifası sınırlıdır.

- $\quad$ Faydalı yük kapasitesi düşüktür.

- İHA ile bağlantının kopması durumunda tehlike oluşturma riski vardır.

- $\quad$ Rüzgâr, yağmur, şimşek vb. hava şartlarından etkilenir (Yiğit, Yazar ve Karakoç, 2018).

\section{Kablolu İHA Sistemleri}

İHA'ların havada kalma sürelerinin kısıtlı olmasına bir çözüm getirmek için birçok girişimci firma yere kablo ile bağlı İHA sistemleri üzerine çalışmalara başlamıştır. Şekil 1'de hava araçları sınıflandırması görülmektedir. Şemada hava araçlarının kullanmakta olduğu havadan ă̆ır tekniği (heavy than air, HTA) ve havadan hafif tekniği (lighter than air, LTA) şeklinde iki ana gruba ayrılır. Bu şemaya göre günümüzde bilinen uçak, helikopter vb. sistemler havadan ağır tekniğini kullanmaktadır. Diğer tarafta görülen havadan hafif tekniğinde ise itkili ve itkisiz sistemler görülmektedir. İtkili sistemler yere bağlı olmayıp, üzerlerinde taşıdıkları 
motorlarla hareket kabiliyetleri daha yüksek olan sistemlerdir. İtkisiz sistemlerde ise yere bağlı olan ve yere bağlı olmayan sistemler görülmektedir.

Kablolu İHA sistemlerini dünya genelinde birçok ülke kullanmaktadır. Bugüne kadar yapılan çalışmalar incelendiğinde İHA'ların havada kalma süresine yönelik iki farklı etkin çözüm bulunmaktadır: Kablolu drone ve kablolu aerostat.

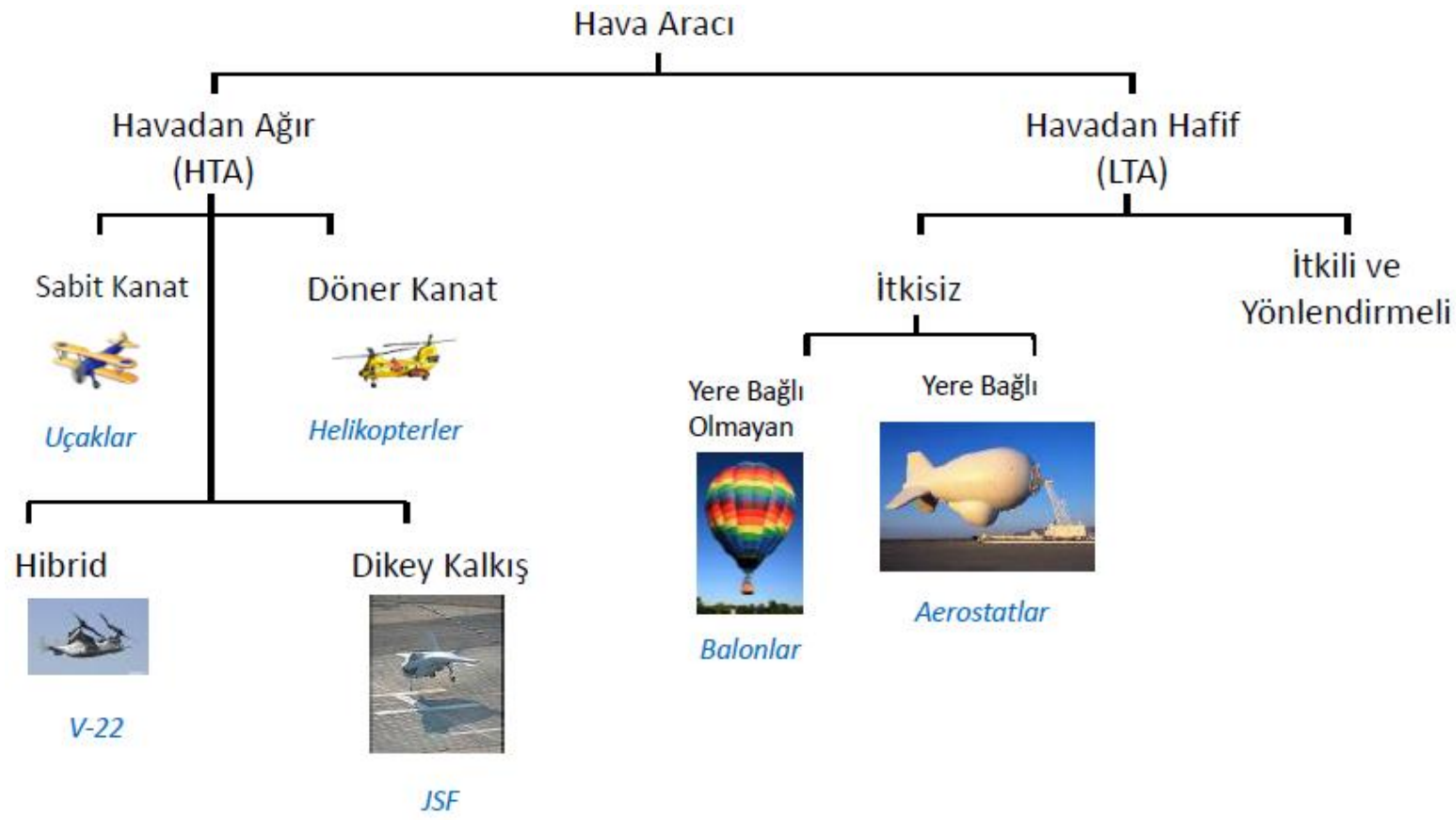

Resim 1. HTA ve LTA Siniflandirması

\subsection{Kablolu Drone}

Döner kanatlı bir İHA'yı kablo ile kompakt bir yer istasyonuna bağlı olarak görev yapabilir hale getiren bir sistemdir. Genel olarak kısıtlı görüş açısına sahip kara ve deniz platformlarında kullanılmaktadır. Drone ile yer kontrol istasyonu arasındaki iletişim kablo hattı üzerinden gerçekleştirildiği için hatta taşınan verilerin çalınması veya karıştırılması büyük oranda engellenmiş olunur. Sisteme ait kablonun kontrolü ve gerekli güç yerde bulunan bir araç ve vinç sistemi vasıtasıyla gerçekleştirilir. Böylece İHA'ya gerekli güç verilerek kesintisiz görev yapması sağlanır (Hoverfly Case Study, 2020). Bu sistemlerde kullanılan Power Line Communication (PLC) haberleşmesi sayesinde gerekli bilgilerin çift yönlü olarak aktarımı mümkündür. Kullanıcı, yer kontrol istasyonu aracılığıyla gerçekleştirilen göreve ait ilgili sensör verilerini, koordinat ve/veya kameradan gelen görüntü bilgilerini anlık olarak izleyebilmektedir. Döner kanatlı İHA sistemlerinin en önemli sorunlarından biri de GPS karıştırmalarının olduğu bölgelerde uçuŞ yapılmasının tehlikeli olmasıdır. Kablolu drone sistemi, belirli algoritmalar ve sensörler kullanarak diğer drone sistemlerine göre GPS verilerine bağlı kalmadan uçuş gerçekleştire-bilmektedir. Şekil 2'de görüldüğü gibi, araç arkası için uygun bir sistem olan kablolu drone sistemi, devriye araçları için olası tehlikeleri erken görüp önlem alınabilmesini sağlamaktadır (Hoverfly Case Study, 2020; Suas News, 2020).

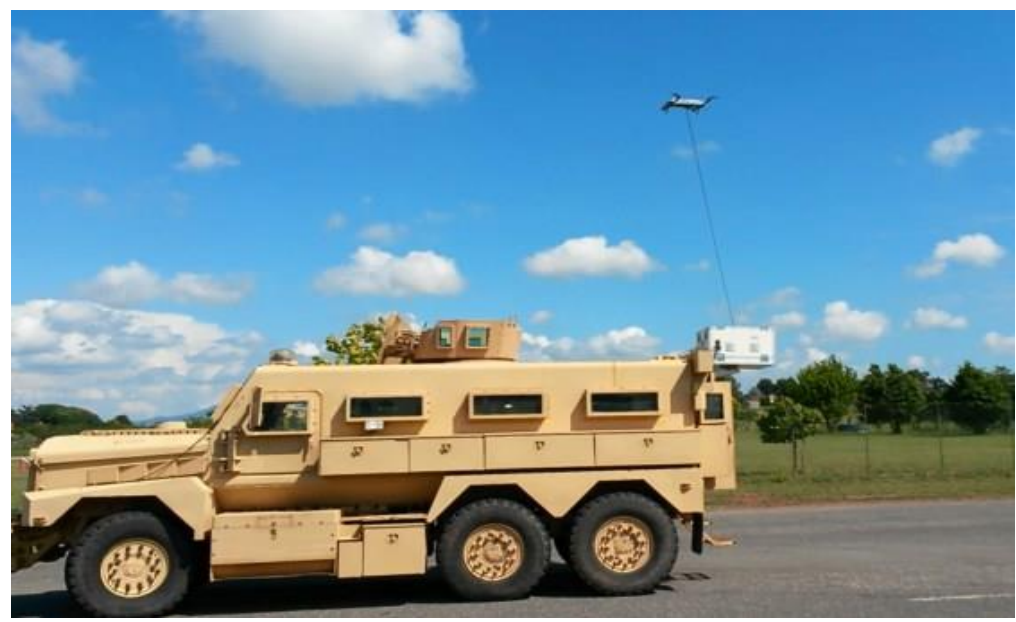

Resim 2. Araç Arkası Kablolu Drone Kullanımı (Hoverfly Case Study, 2020) 


\subsection{Kablolu Aerostat}

Kablolu aerostat sistemi, havadan hafif tekniği baz alınarak göreve özel olarak tasarlanmaktadır (Peterson, 2005). Havadan hafif tekniğinde sistem çevresindeki havadan daha hafif olan bir gaz ile doldurularak havanın kaldırma kuvveti kullanılır. Aerostat sistemlerinde geçmişte hidrojen gazını kullanmış olsa da günümüzde daha güvenli olduğu bilinen helyum gazı kullanılmaktadır (Kapoor ve Pant, 2013).

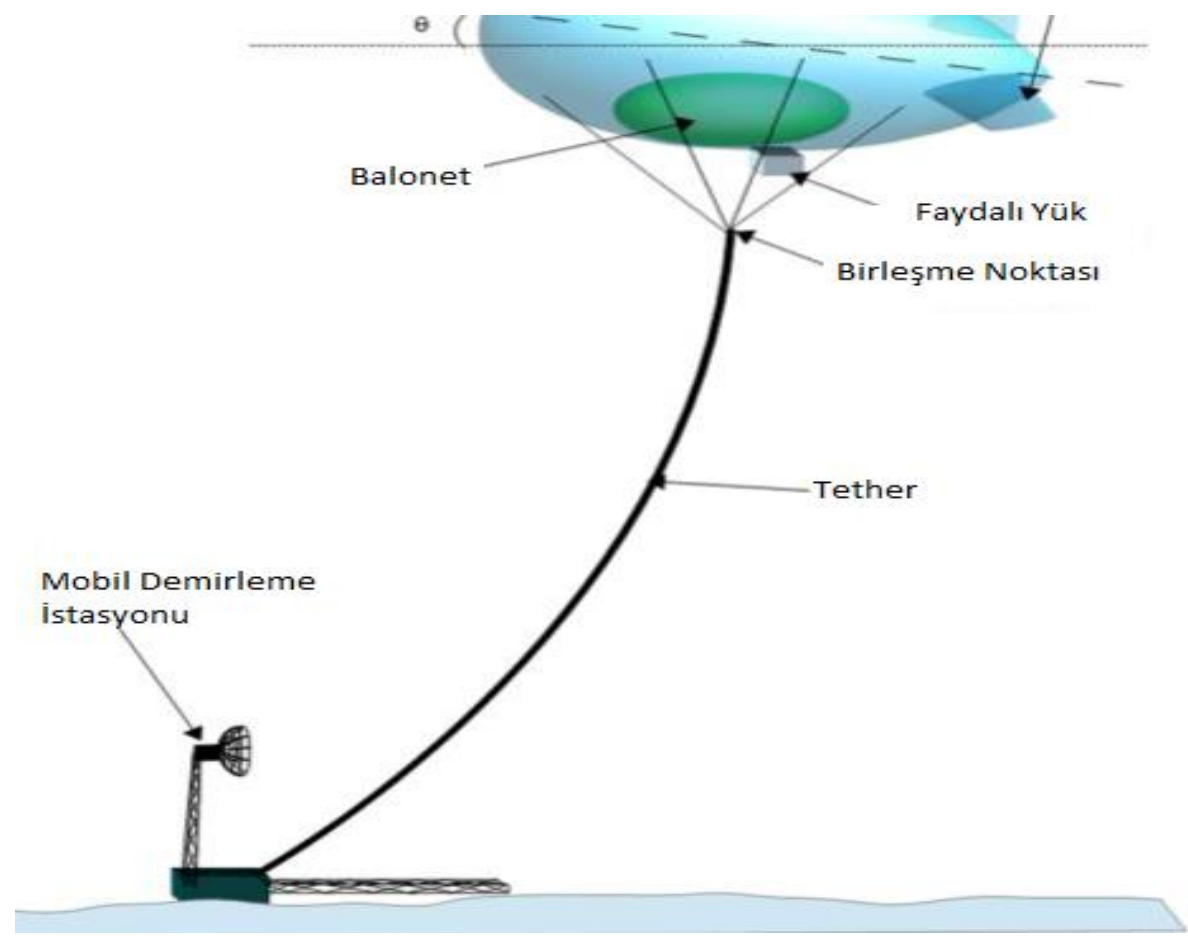

Resim 3. Aerostat Sistemi ((Bajoria ve ark., 2017)

Aerostat sistemleri helyum gazının bulunduğu balon ve havanın bulunduğu balonet bölümlerinden oluşmaktadır. Balonet üzerinde hava alışverişini sağlayan valf ve üfleç sistemleri bulunmaktadır. İstenilen irtifalara yükselebilmek ve belirli bir irtifadan alçalabilmek için balonet kısmına, valf ve üfleçler yardımıyla hava girişi ve çıkışı yapılarak balon içerisinde bulunan helyum gazının basıncı değiştirilmiş olunur. Bu tür sistemler aerostatın bağlı olduğu mobil bir demirleme istasyonuna ihtiyaç duymaktadır. Mobil demirleme istasyonu ile aerostat sistemi arasındaki tether adı verilen kablo, yüksek çekme kuvvetlerine dayanabilecek şekilde tasarlanmaktadır. Tether kablosu içerisinde bir güç hattı ve iki adet fiber hattı bulunmaktadır. Güç hattı üzerinden kesintisiz güç verilerek sistemin uzun süre havada kalması sağlanabilmektedir (Peterson, 2005; Kapoor ve Pant, 2013).

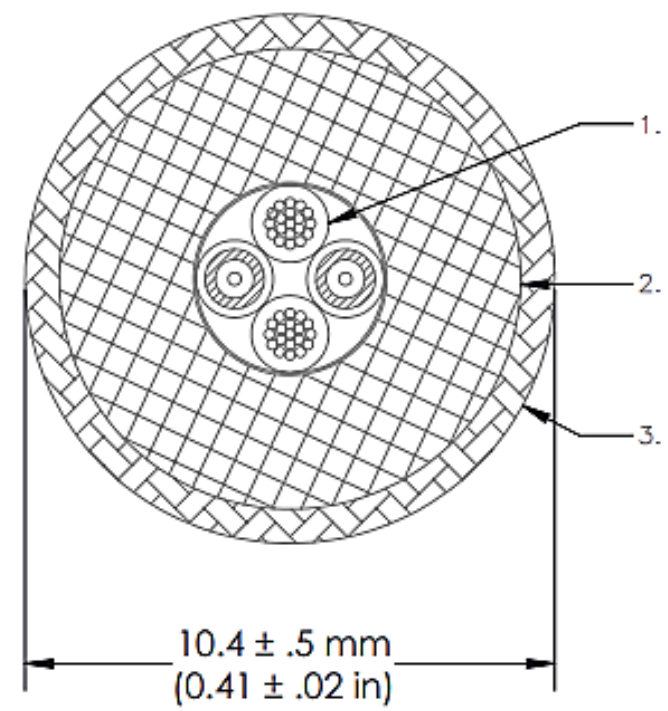

Resim 4. Örnek Bir Tether Kablo Kesiti (Hybrid Cable datasheet) 
Resim 4 'te yer alan kablo kesitinde 1 numaralı alan güç ve fiber hattının geçtiği kablonun ana kısmıdır, 2 numaralı kısım kablonun mukavemetini arttıran vectran örgü yapısına sahip bir iç kılıftır. 3 numaralı bölge ise örgülü polyester yapıya sahip bir dış kılıftır. İç içe geçmiş bu 3 bölge aerostat sistemi için belirlenen irtifalara güç ve veri aktarımını sağlar.

Bu sistemlerin en büyük avantajlarından biri de sistemin oldukça sessiz çalışması ve diğer İHA sistemlerine kıyasla radar kesit alanının minimum düzeyde olmasıdır. Bu sayede keşif, gözetleme ve istihbarat çalışmalarında oldukça kullanışlı bir sistem durumuna gelmektedir. Yüksek irtifaya çıkan aerostat sisteminin bir diğer avantajı ise yer radarı ve elektro-optik sistemlerinden çok daha geniş bir görüş açısına sahip olmalarıdır (Cimsec, 2020).

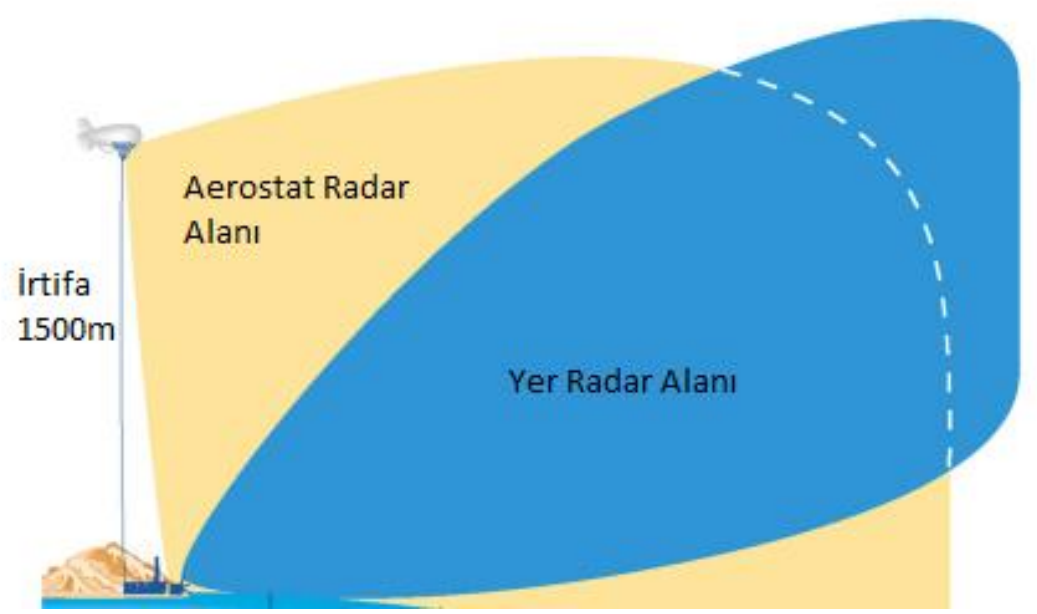

Resim 5. Aerostat ve Yer Sistemlerinin Görüş (Cimsec, 2020)

\subsection{Kablolu İHA Uygulama Alanları}

Kablolu İHA sistemleri faydalı yük taşıyabilme kabiliyeti sayesinde birçok görevde kullanılabilmektedir. Özellikle kablolu aerostat sistemi 500 kg’ye kadar faydalı yük taşıyabilme kapasitesine sahiptir. Bu faydalı yükler göreve özgü değişebilmekle beraber genel olarak radar, kamera, anten ve çeşitli özel amaçlı sistemlerden oluşmaktadır (Deschênes ve Nahon, 2005).

Kablolu İHA sistemleri genel olarak aşağıdaki alanlarda faaliyet göstermektedir:

- Haberleşme

- Kritik tesis güvenliği

- Keşif, gözetleme, istihbarat

- Çevre koruma

- Deniz ve liman trafiği

- Sinır güvenliği vb.

\section{Sonuç}

Kablolu İHA sistemlerinin kullanımı her geçen gün yaygınlaşmaktadır. Bunda en büyük etken sistemin kablo ile kesintisiz gü̧̧ sağlayarak kullanıcıyı kısıtlı uçuş sürelerinden kurtarmış olmasıdır. Ayrıca sistemin veriyi kablo üzerinden taşıması sayesinde taşınan verinin karıştırılması ve/veya dinlenmesi büyük ölçüde engellenmiş olur. Sınır güvenliği, keşif ve gözetleme, haberleşme, aramakurtarma ve kritik tesis güvenliği gibi geniş bir yelpazedeki farklı ihtiyaçlar için, uzun süre boyunca havada kalabilme kabiliyetine sahip olan kablolu İHA sistemleri, normal bir döner kanatlı İHA veya sabit kanatlı İHA'ya göre daha avantajlı hale gelmektedir. Bu sistemlerin yerde belirli bir noktaya bağlı olmaları nedeniyle operasyon alanının sınırlı olması bir dezavantaj gibi gözükse de uygulamaya yönelik olarak sağladığı faydalı yük kapasitesi ve havada kalma sürelerinin fazla olması kablolu İHA sistemlerini tercih edilir hale getirmektedir (YIlmaz ve Gencer, 2018).

İHA sistemlerinin maliyetleri ve uçuş süreleri düşünüldüğünde hem maliyet etkin olması hem de uzun süre boyunca havada kalma kabiliyeti sayesinde kablolu İHA sistemleri oldukça kullanışlı hale gelmektedir. Yüksek ağırlıkta faydalı yük taşıyabiliyor olmaları sayesinde aynı operasyonda birden fazla faydalı yükü taşıyarak, kullanıcıya aktif olarak kullanabilme imkânı sağlamaktadırlar. Son yıllarda ülkemizde de kullanım alanlarının yaygınlaşmasıyla birlikte Aselsan, Türksat ve Otonom Teknoloji firmaları bu alanda çalışmalar yaparak bu platformları Türkiye'de üretilir ve kullanılır hale getirmektedir (Karaağaç, 2016). 


\section{Kaynakça}

Kabadayı, A. \& Uysal, M. (2019), İnsansız Hava Aracı ile Elde Edilen Verilerden Binaların Tespiti , Türkiye IHA Der., 1(1): 08-14

Bayraktar, E. (2013), Design and Control of an Autonomous Blimp , E.E Müh. Yüksek Lisans Tezi, İstanbul Teknik Üniversitesi, Fen Bilimleri Enstitüsü

Bajoria, A., Mahto, N.K., Boppana, C.K. \& Pant, R.S. (2017), Design of a Tethered Aerostat System for Animal and Bird Hazard Mitigation, ICRAAE, paper: 8297244

Balasubramanian, P., Sati, S.C., Pal, A. \& Gautam, R. (2014), A Novel Method For Improving Aerostat Endurance Using Microprocessor Controlled Feedtube, International Journal of Advances in Science Engineering and Technology, 2(3): 114-120

Pant, R., Komerath, N. \& Kar, A. (2011), Application of Lighter-Than-Air Platforms for Power Beaming, Generation and Communications , International Symposium on Electronic System Design, paper: 10.1109

Karaağaç, C. (2016), İHA Sistemleri Yol Haritası: Geleceğin Kartalları 2016-2050, Savunma Teknolojileri Mühendislik ve Ticaret A.Ş.

Yiğit, E., Yazar, I. \& Karakoç, T.H. (2018), İnsansız Hava Araçları (İHA)'nın Kapsamlı Sınıflandırılması ve Gelecek Perspektifi, Sürdürülebilir Havacılık Araştırmaları Dergisi, 3(1): 13-19

Airforce-Technology, https://www.airforce-technology.com/features/featurethe-top-10-longest-range-unmanned-aerial-vehicles-uavs/, E.T. 07.09.2020.

St Endustri, https://www.stendustri.com.tr/makina/aksungur-dan-49-saatlik-ucus-h107851.html, E.T. 05.09.2020.

Hoverfly Case Study, http://b63.b67.myftpupload.com/wp-content/uploads/2018/03/Hoverfly-Case-Study-in-March-SM.pdf, E.T. 08.09.2020.

Suas News, https://www.suasnews.com/2014/09/italian-army-is-evaluating-a-tethered-uav-for-convoy-protection/, E.T. 12.09.2020.

Peterson, S. (2005), The small aerostat system: Field tested, highly mobile and adaptable, AIAA 5th Aviation, Technology, Integration, and Operations Conference (ATIO), paper 2005-7444

Kapoor, A. \& Pant, R.S. (2013), A Methodology for Conceptual Sizing of a Tethered Aerostat, AIAA Lighter-Than-Air Systems Technology (LTA) Conference, paper 2013-1274

Hybrid Cable datasheet, Cortland Company, Canada.

Cimsec, http://cimsec.org/strategic-role-tactical-maritime-aerostats-ensuring-persistent-surveillance/26214, E.T. 14.09.2020.

Deschênes, F. \& Nahon, M. (2005), Design Improvements for a Multi-Tethered Aerostat System, AIAA Atmospheric Flight Mechanics Conference, paper 6126

Yilmaz, N. \& Gencer, C.T. (2018), Where To Locate Tethered Aerostats for an Effective Surveillance System: A Case Study on Southern Turkey, GU J Sci, 31(1): 189-200 